\title{
Increased CA 125 in a patient with tuberculous peritonitis: case report and review of published works
}

\author{
D K O’Riordan, A Deery, A Dorman, O E Epstein
}

\begin{abstract}
A case of a middle aged woman with weight loss, ascites, and a pleural effusion is presented where a clinical diagnosis of ovarian cancer was made. Her CA 125 was greatly increased at $873 \mathrm{IU} / \mathrm{ml}$ and the ascites was a lymphocytic exudate but cytology failed to show malignant cells. Operative biopsy showed numerous noncaseating granulomas in the omentum but no mycobacterial organisms were seen. Empiric antituberculous treatment was started before positive culture results were received and when treatment had ended both the ascites and pleural effusion had resolved and the CA 125 had fallen to $7 \mathrm{IU} / \mathrm{ml}$. Review of published works showed several other examples of tuberculous peritionitis associated with increased CA 125 and the possible cause of raised CA 125 in this condition is discussed.

(Gut 1995; 36: 303-305)
\end{abstract}

Keywords: peritonitis, tuberculosis, CA 125.

Case report

A 55 year old Indian woman presented with a two month history of abdominal distension, shortness of breath, and right sided chest pain. She was anorexic and had noticed a $10 \mathrm{~kg}$ loss of weight. On examination she had signs of a right pleural effusion and considerable ascites. Tuberculosis seemed to be the most likely diagnosis.

Two years previously she had been referred with epigastric pain and weight loss. Duodenitis was diagnosed and she required maintenance treatment with $\mathrm{H}_{2}$ antagonists for six months. Her symptoms recurred when treatment ended. Endoscopy showed

\section{Departments of \\ Medicine \\ D K O'Riordan \\ O E Epstein}

Histopathology A Dorman

and Cytology

A Deery

Royal Free Hospital and Royal Free Hospital School of Medicine, London

Correspondence to: Dr D K O'Riordan, Department of Medicine, Royal Free Hospital, Pond Street, London NW3 2QG.

Accepted for publication 27 May 1994

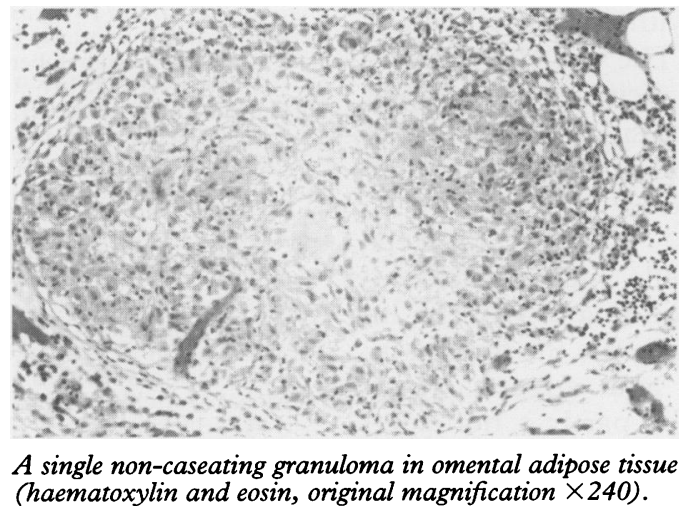

(haematoxylin and eosin, original magnification $\times 240$ ). oesophagitis and omeprazole had been prescribed. Full blood count was normal apart from mild lymphopaenia. Urea and electrolytes, liver function tests, and clotting were normal.

Chest $x$ ray confirmed a large right sided pleural effusion (not present on a film taken in 1989). Mantoux test at $1: 10000$ and $1: 1000$ were negative. Computed tomography of abdomen and pelvis showed ascites. Pelvic ultrasound identified a small transonic area in the left ovary and fluid in the pouch of Douglas but no adnexal masses. Paracentesis showed a predominantly lymphocytic exudate. No malignant cells were seen and no organisms identified or grown from repeated taps. Pleural fluid analysis was similar to the peritoneal fluid. Serum tumour marker assays were CEA $7 \mu \mathrm{g} / \mathrm{l}(\mathrm{N}<10)$, CA 19/9 $13 \mathrm{U} / \mathrm{ml}(\mathrm{N}<30)$, CA $125873 \mathrm{U} / \mathrm{ml}(\mathrm{N}<35)$.

As a result of the extremely high concentration of CA 125 a diagnostic laparotomy was performed with the expectation of finding ovarian cancer. The omentum was adherent to the anterior abdominal wall and the peritoneal surfaces were covered with fine 'deposits'. The ovaries were normal and there were no palpable masses in the large or small bowel. The pancreas was normal. The caecum was thickened. An omental biopsy was taken for histological examination and culture. Macroscopically the specimen was mainly composed of fatty tissue (Figure). The cut surface was lobulated and covered by fine white deposits.

On microscopy numerous non-caseating granulomas with Langhans' giant cells were seen but no acid fast bacilli were identified. The appearances were suggestive of tuberculosis with the lesser possibility of sarcoidosis. Repeat pleural tap and pleural biopsy were not diagnostic.

At this stage we decided to treat empirically for tuberculosis and triple therapy was started with rifampicin, isoniazid (with pyridoxine), and pyrazinamide. Shortly after discharge mycobacterium tuberculosis was cultured from pleural fluid but not from ascites. Eight weeks after treatment had begun the ascites and pleural effusion had resolved. On completion of treatment CA 125 concentrations were normal.

Cytospin preparations from the pleural and peritoneal fluids were retrospectively analysed immunocytochemically for the presence of CA 125 with a monoclonal antibody. Positive and negative controls were included composed of similar cytospins of ascitic fluid 
Case reports of increased $C A 125$ with tuberculous peritonitis

\begin{tabular}{lc}
\hline Imai et al & $1400 \mathrm{U} / \mathrm{ml}$ \\
Ronay et al & $290 \mathrm{U} / \mathrm{ml}$ and $264 \mathrm{U} / \mathrm{ml}$ (2 cases) \\
Okazaki et al & $1054 \mathrm{U} / \mathrm{ml}$ \\
Gurgan et al & $369.5 \mathrm{U} / \mathrm{ml}$ and $402 \cdot 6 \mathrm{U} / \mathrm{ml}$ (2 cases) \\
\hline
\end{tabular}

incorporating ovarian carcinoma and without primary antibody application respectively. No staining was identified in any of the lymphocytic, histiocytic or mesothelial populations included in either the pleural or ascitic fluid.

\section{Discussion}

Abdominal tuberculosis is rare in the developed world except among immigrants and cirrhotic patients. The most common form is tuberculous peritonitis, which occurs in 0.1 to $0.7 \%{ }^{1}$ of all cases of tuberculosis and in $2 \%$ of cases in the developing world. The most interesting aspect of our case was the considerable increase in CA 125. This together with the clinical presentation and negative Mantoux test led us to suspect overian cancer. CA 125 is a soluble glycoprotein oncofetal antigen to which a monoclonal antibody has been raised. This protein is increased in $82 \%$ of patients with ovarian cancer and in only $1 \%$ of controls. ${ }^{2}$ The upper limit of normal for CA 125 is given as $32 \mathrm{U} / \mathrm{ml}$ although a value of $65 \mathrm{U} / \mathrm{ml}$ has been suggested to give better specificity for ovarian cancer. Together with pelvic ultrasound CA 125 is $99.8 \%$ specific for ovarian cancer. ${ }^{3}$ CA 125 is, however, also raised in some instances in endometriosis, ${ }^{4}$ pelvic inflammatory disease, and pregnancy. ${ }^{5}$ There are reports in cases of 'miliary tuberculosis and ascites' by two groups in Germany $^{6} 7$ and in further reports from Japan $^{89}$ and Turkey. ${ }^{10}$ The Table lists the concentrations of CA 125 in these cases.

CA 125 may be increased in patients with tuberculous associated pleural effusions but the concentration falls significantly after one to two months of antituberculous treatment. ${ }^{11}$ It is also increased in tuberculous associated pericarditis. ${ }^{12}$

CA 125 is raised in many diseases of the gastrointestinal tract. These have been comprehensively reviewed at a recent symposium. ${ }^{13}$ The commonest occurrences of raised CA 125 were in cirrhosis and peritonitis though it is also noted in tumours of the upper and lower bowel, pancreatitis, hepatitis, and inflammatory bowel disease. In cirrhosis the CA 125 value correlates with the degree of liver failure by Child's grade. The CA 125 value is higher in cirrhosis with ascites than without and falls after paracentesis but not with diuretic treatment suggesting the peritoneum as the source of the antigen. ${ }^{14}$

Immunohistochemical staining detects CA 125 in carcinoma cells and in activated mesothelial cells. ${ }^{15}$ The finding of CA 125 in pleural mesothelial cells mirrors the finding in peritoneal lining cells and suggests that increased CA 125 may be partly a non-specific marker of inflammation or trauma. ${ }^{16}$

We could find no evidence of CA 125 immunocytochemically in either the granulomas from the biopsy material or in cytospin preparations of pleural and ascitic fluid with good positive controls in both cases. Therefore we cannot confirm previous findings in this regard and the source of the CA 125 in this case remains to be found. The serum CA 125 concentration, however, did return to normal after antituberculous treatment.

This case highlights the difficulty of diagnosing abdominal tuberculosis in some instances. The onset is usually insidious although presentation as an acute abdomen has been described. ${ }^{17}$ The commonest symptoms are abdominal swelling, weight loss, and abdominal pain. Acid fast bacilli are rarely detected, though Singh et al reported 83\% success when large volumes of ascitic fluid were cultured. ${ }^{18}$ Chest $x$ ray is abnormal in only $40-50 \%$ of cases. Mantoux testing is positive in $70 \%$ of patients. Adenosine deaminase is reported to be a useful marker for both peritoneal and pleural tuberculosis. ${ }^{19} 20$ Definitive diagnosis still depends on finding caseating granulomas on biopsy. Laparoscopy seems to be the most effective way to obtain a diagnosis. ${ }^{21}$ In our case the operative findings were consistent with tuberculosis but the biopsy showed non-caseating granulomas. This report shows that very high concentrations of CA 125 can occur in conditions other than carcinoma of the ovary and that tuberculosis needs to be considered in the differential diagnosis of ascites with raised tumour markers. This is especially important as tuberculosis is a curable disease, which is becoming increasingly common and more resistant to treatment. ${ }^{22}$

1 Vyravanathan S, Jeyarajah R. Tuberculous peritonitis: a review of thirty-five cases. Postgrad Med 7 1980; 56: $649-51$.

2 Bast RC, Klug TL, St John E, Jenison E, Niloff JM, Lazarus $\mathrm{H}$, et al. A radioimmunoassay using a monoclonal antibody to monitor the course of epithelial ovarian cancer. body to monitor the course of epit

3 Jacobs I, Stabile I, Bridges J, Kempley P, Reynolds C, Grudzinkas J, et al. Multimodal approach to screening for ovarian cancer. Lancet 1988; i: 268-71.

4 Barbieri RI, Niloff JM, Bast RC, Schaetzl E, Kistner RW, Knapp RC. Elevated serum concentrations of CA 125 in patients with advanced endometriosis. Fertil Steril 1986; 45: 630 .

5 Halila H, Stenman U-K, Seppala M. Ovarian cancer antigen CA-125 levels in pelvic inflammatory disease and pregnancy. Cancer 1986; 57: 1327-9.

6 Klein M, Marczewski A, Rosen A, Beck A. High CA 125 values in miliary tuberculosis and ascites. Wien Klin values in miliary tuberculosi
Wochenschr 1989; 101: 870-1.

7 Ronay G, Jager W, Tulusan AH. Immunohistochemical and serological detection of CA-125 in patients with peritoneal tuberculosis and ascites. Geburtshilfe Frauenheilkd 1989; 49: $61-3$.

8 Okazaki K, Mizuno K, Katoh K, Hashimoto S, Fukuchi S. Tuberculous peritonitis with extraordinarily high serum CA 125. ₹ Med 1992; 23: 353-61.

9 Imai A, Itoh T, Niwa K, Tamaya T. Elevated CA 125 levels in a patient with tuberculous peritonitis. Arch Gynecol Obstet 1991; 248: 157-9.

10 Gurgan T, Zeyneloglu H, Urman B, Develioghu O, Yarali $H$. Pelvic-peritoneal tuberculosis with elevated serum and peritoneal fluid CA 125 levels. Gynecol Obst Invest 1993; 35: $60-1$.

11 Nakanishi Y, Hiura K, Katoh O, Yamaguchi T, Kuroki S, Aoki Y, et al. Clinical significance of serum CA 125 in patients with tuberculous pleurisy. Kekkaku 1991; 66: patients

12 Cacoub P, Le Thi HD, Wechster B, Chapelon C, Auperin A, Gandjbakch I. Chronic constrictive pericarditis responsible for an increase of CA 125 levels. Two cases. Presse Med 1990; 19: 1712-4.

13 Ruibal Morrell A, Fernandez Llana B, Alvarez A, Allende MT. Anticancer Res 1993; 13: 1717-20.

14 Molina R, Filella X, Jo J, Deulofeu R, Joseph J, Ballesta AM. Anticancer Res 1993; 13: 1685-90.

15 Tomita Y. Clinical evaluation and tissue distribution of CA 
125 in patients with pleural effusion. Igaku Kenkyu 1989; 59: 90-6.

16 Redman CWE, Jones SR, Luesley DM, Nicholl SE, Kelly $\mathrm{K}$, Buxton EH, et al. Peritoneal trauma releases CA 125? Br f Cancer 1988; 58: 502-4.

17 Khoury GA, Payne CA, Harvey DR. Tuberculosis of the peritoneal cavity. Br F Surg 1978; 65: 808-11.

18 Singh MM, Bhargava AN, Jain KP. Tuberculosis peritonitis. An evaluation of pathogenetic mechanisms, diagnostic procedures and theraputic measures. $N$ Engl $\mathcal{F}$ Med 1969; 281: 1091-4.

19 Martinez-Vasquez JM, Ocana I, Ribera E, Segura RM, Pasqual C. Adenosine deaminase activity in the diagnosis of tuberculosis peritonitis. Gut 1986; 27: 1049-53.
20 Banales JL, Pineda PR, Fitzgerald JM, Rubio H, Selman M, Salazar-Lezama $\mathbf{M}$, et al. Adenosine deaminase in the diagnosis of tuberculous pleural effusions. A report of 218 patients and review of the literature. Chest 1991; 99: 355-7.

21 Manohar A, Simjee AE, Haffejee AA, Pettengell KE Symptoms and investigative findings in 145 patients with tuberculous peritonitis diagnosed by peritoneoscopy and biopsy over a five year period. Gut 1990; 31: $1130-2$.

22 Frieden TR, Sterling T, Pablos-Mendez A, Kilburn JO, Cauthen GM, Dooley SW. The emergency of drug resistant tuberculosis in New York City. N Engl $\mathcal{F}$ Med 1993; 328: 521-6. 